E International

\title{
The 'Grand Paris' Project: Tools and Challenges
}

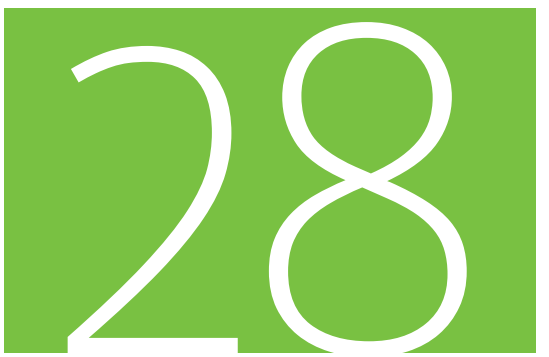

Discussion Paper 2011 • 28

André DE PALMA

École Normale Supérieure de Cachan,

France 


\title{
The "Grand Paris" Project: Tools and Challenges
}

\author{
Discussion Paper No. 2011-28
}

\begin{abstract}
Prepared for the Roundtable on:
"Major Transport Infrastructure Projects and Regional Economic Development - Assessment and Implementation"
\end{abstract}

(1-2 December 2011, Paris)

\section{André DE PALMA}

Ecole Normale Supérieure de Cachan, France

November 2011 


\section{INTERNATIONAL TRANSPORT FORUM}

The International Transport Forum at the OECD is an intergovernmental organisation with 52 member countries. It acts as a strategic think-tank, with the objective of helping shape the transport policy agenda on a global level and ensuring that it contributes to economic growth, environmental protection, social inclusion and the preservation of human life and well-being. The International Transport Forum organises an annual summit of Ministers along with leading representatives from industry, civil society and academia.

The International Transport Forum was created under a Declaration issued by the Council of Ministers of the ECMT (European Conference of Ministers of Transport) at its Ministerial Session in May 2006 under the legal authority of the Protocol of the ECMT, signed in Brussels on 17 October 1953 , and legal instruments of the OECD.

The members of the Forum are: Albania, Armenia, Australia, Austria, Azerbaijan, Belarus, Belgium, Bosnia-Herzegovina, Bulgaria, Canada, Croatia, the Czech Republic, Denmark, Estonia, Finland, France, FYROM, Georgia, Germany, Greece, Hungary, Iceland, India, Ireland, Italy, Japan, Korea, Latvia, Liechtenstein, Lithuania, Luxembourg, Malta, Mexico, Moldova, Montenegro, the Netherlands, New Zealand, Norway, Poland, Portugal, Romania, Russia, Serbia, Slovakia, Slovenia, Spain, Sweden, Switzerland, Turkey, Ukraine, the United Kingdom and the United States.

The International Transport Forum's Research Centre gathers statistics and conducts co-operative research programmes addressing all modes of transport. Its findings are widely disseminated and support policymaking in member countries, as well as contributing to the Annual Summit.

\section{Discussion Papers}

The International Transport Forum's Discussion Paper Series makes economic research, commissioned or carried out at its Research Centre, available to researchers and practitioners. The aim is to contribute to the understanding of the transport sector and to provide inputs to transport policy design. The Discussion Papers are not edited by the International Transport Forum and they reflect the author's opinions alone.

The Discussion Papers can be downloaded from:

www.internationaltransportforum.org/jtrc/DiscussionPapers/jtrcpapers.html

The International Transport Forum's website is at: www.internationaltransportforum.org

For further information on the Discussion Papers and other JTRC activities, please email:

itf.contact@oecd.org 


\section{SUMMARY}

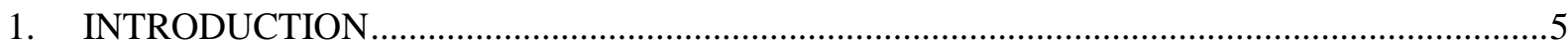

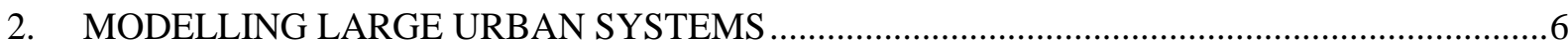

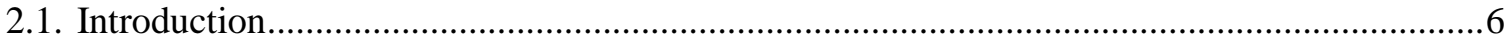

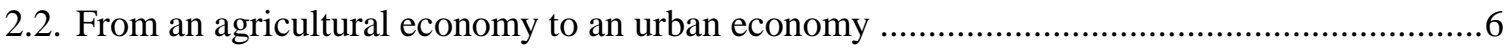

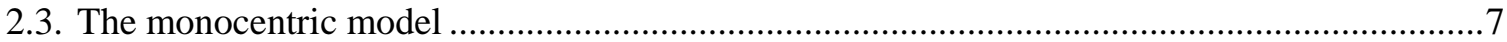

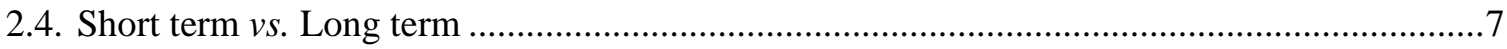

2.5. Spatial competition - monopolistic and oligopolistic ............................................................

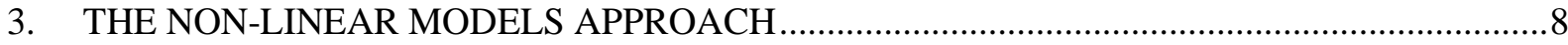

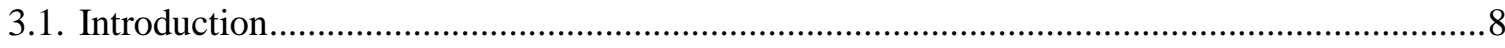

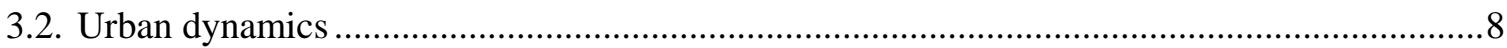

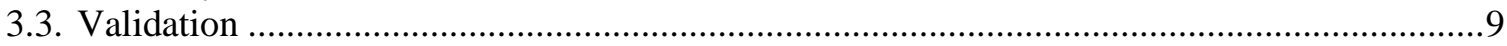

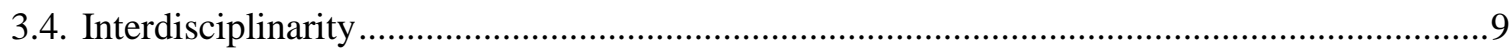

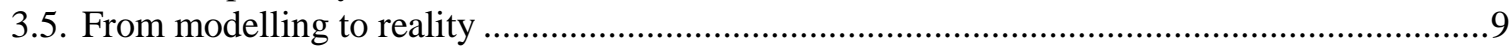

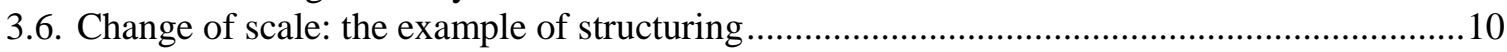

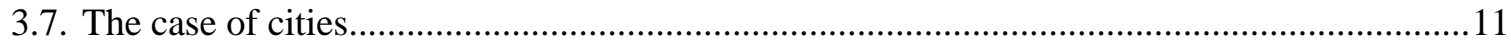

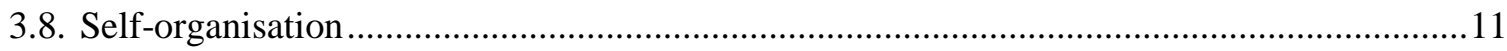

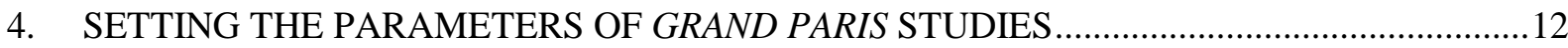

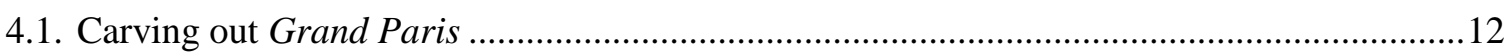

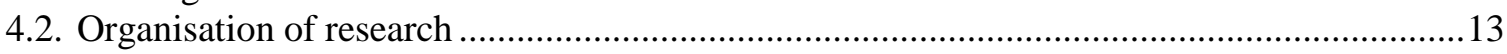

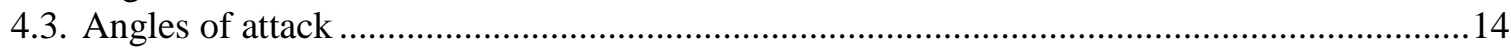

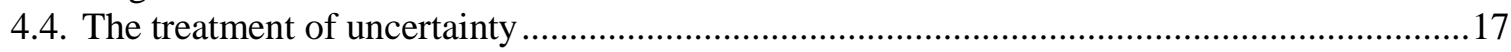

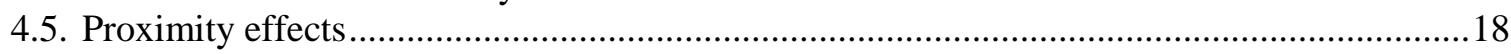

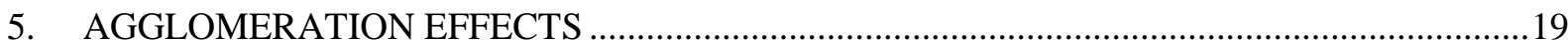

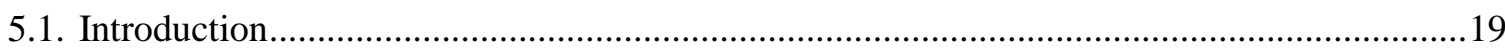

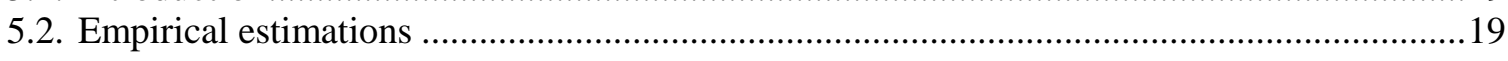

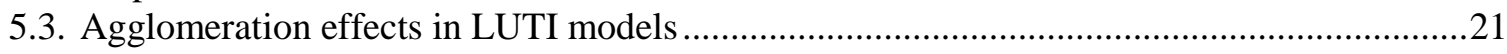

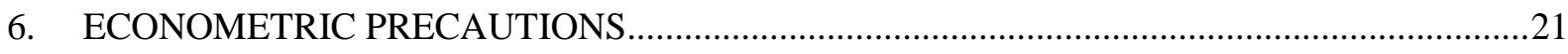

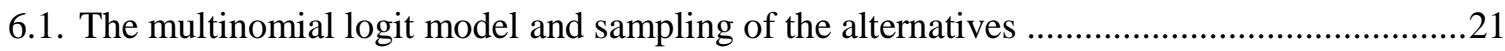

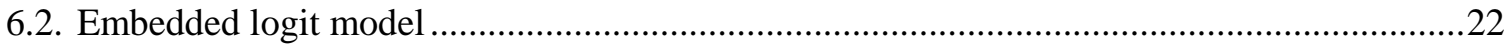

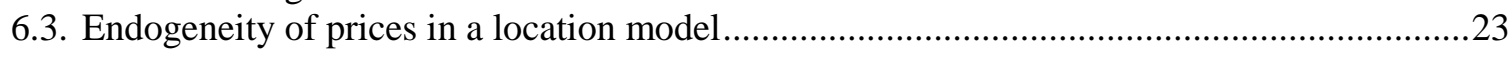

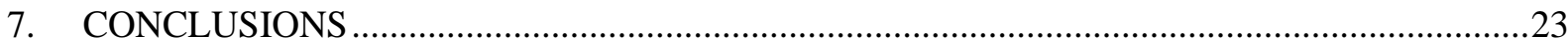


A. de Palma - Discussion Paper No. 2011-28 - (C) OECD/ITF, 2011 


\section{INTRODUCTION ${ }^{1}$}

The purpose of this Round Table is to assess the economic effects of major transport infrastructure projects. The term "major projects" is used to designate qualitative leaps, be it the mapping out of new road or rail rings to link disparate radial penetration routes or the introduction of more-targeted innovations tackling frequency, speed or automation.

As our hosts wisely remind us, there is more involved here than extending the list of the direct effects of such projects in terms of enhanced accessibility. One must also factor in the productivity gains arising from agglomeration effects, without neglecting the indirect effects, which involve the shifting urban structure and the modulation of growth.

On what conditions can we deliver growing economies of scale and ensure complementarities in public/private partnerships? How should we take part in discussions to define well-being indicators that can supplement and redefine growth indicators? These are new directions for our research.

In this article, we shall summarise a number of major aspects of the project that concerns us here, as it relates to transport infrastructure and its interaction with urban dynamics.

But first, let us briefly review the main features of the Grand Paris adventure. In September 2007, French President Nicolas Sarkozy enshrined the idea of a "new comprehensive development project for Greater Paris". One provision of the Act of 3 June 2010 was to establish the Société du Grand Paris (SGP) as lead contractor in charge of designing the transport project and getting it built.

This project will consolidate and make trade-offs between a number of different ideas. A regional train or express Metro will link Charles de Gaulle and Orly airports and will endow the region with rings around the outer periphery, without neglecting the south-west and its centres of excellence (Palaiseau, Saclay, Versailles). The aggregate daily flow is soon expected to reach millions of travellers.

This undertaking is the result of assessments in the realms of economics, demographics and urban planning:

$>$ The GDP of the Île-de-France region grew by an average of $2 \%$ per year between 2000 and 2008, which is low in comparison with the 3 to $4 \%$ of New York or London. Furthermore, despite economic vitality, few jobs are being created.

$>$ Population growth in Île-de-France is around the national average as a result of strong natural growth but negative net migration due to heavy outflows to other parts of the country.

$>$ The urban spread induced by the Villes Nouvelles ("New Towns") policy is substantial, resulting in poor mass transit services, high road congestion costs, passive and active spatial segregation and a decline in agricultural zoning. Large differences in population density can be observed between Paris $\left(25000 / \mathrm{km}^{2}\right)$ and the outer periphery $\left(1000 / \mathrm{km}^{2}\right)$, but recent 
trends, between 1990 and 2006, show rapid growth on the periphery. Public services and infrastructure are distributed poorly.

$>$ There are numerous trips from suburb to suburb, many of which in passenger cars ${ }^{2}$, including trips to airports and railway stations.

Greenhouse gas emissions need to be controlled.

The project links eight major development hubs in Île-de-France and is lending support to their growth (see Section 4). It is estimated to generate population and job growth of respectively 1.5 million and 1 million by $2030^{3}$. Thanks to this new infrastructure, mobility and service will be extended by connections with all existing lines and an expansion of suburb-to-suburb services. An indirect aim of the project is to generate economic and urban vitality, especially in the project areas cited above, some of which are currently isolated. The projected cost is estimated at some EUR 20 billion ${ }^{4}$.

In this article we shall describe how integrated land-use and transport interaction (LUTI) models may be used to assess the (local, regional and international) impacts of transport infrastructure projects.

\section{MODELLING LARGE URBAN SYSTEMS}

\subsection{Introduction}

The new wave of modelling large urban systems is in fact grounded in a tradition of theoretical reasoning, the main thrusts of which we shall outline briefly below. This is not a history (dealt with masterfully by Thisse, 2011), but it can be used to reconstitute the pathways that led to models that seek to describe large cities.

\subsection{From an agricultural economy to an urban economy}

A number of the key concepts that led to the urban economy had been examined in works published since the beginning of the $20^{\text {th }}$ century on spatial organisation in connection with farming operations and the distribution of urban hierarchies (von Thünen, 1826; Lösch, 1940; Christaller, 1933). An agronomist, von Thünen, uses a system of concentric rings to describe the mechanisms of land allocation through a bidding process (land being allocated to the highest bidder in a context of perfect competition). An economist, Lösch, begins with an isotropic plane in which self-sufficient entities maximise their accessibility to certain goods and services, and he explores the gradual organisation of the circulation of goods, services and persons. 


\subsection{The monocentric model}

The application of these ideas of bidding and optimisation to the framework of urban economics can be associated with Alonso (1964) ${ }^{5}$. Alonso (along with Richard Muth and later Edwin Mills) helped establish the monocentric model of the city, in which all workers travel each morning to a single working location known as the central business district (with regard to this, see the review by Quigley, 2008). This model, which assigns jobs to the city centre, therefore describes only the residential choices of households. It is nonetheless still useful for understanding household location and urban spread mechanisms (see preliminary studies by Chiappori, de Palma and Picard, 2011).

\subsection{Short term vs. Long term}

Recent literature shows how the introduction of cordon pricing in Île-de-France can affect the structure of the city, urban spread and congestion (de Palma et al. 2011). These authors use a monocentric model with automobile traffic congestion. This model was adjusted to the data available from Île-de-France to explain urban spread. Comparable studies were conducted over the short term (holding household residence constant) and the long term (residence variable). These show that pricing effects are only half as great in the short term as over the long term. This figure is only a rough approximation, yet it indicates the utility of factoring in the relocation processes of households and businesses.

Incorporating major policy choices entails detailed modelling of transport systems as well as business relocation modelling (which is disregarded in the monocentric model but included in polycentric models, which are more complex). This militates for the integrated transport/land use models that we shall be discussing later.

In a more elaborate model, it is necessary to introduce the spatial externalities that affect households and businesses. Symmetrically, the mobility decisions of households and businesses effectively alter (and are affected by) density values and thus externalities. These externalities, which are difficult to quantify (except in respect of congestion), are to a great extent disregarded by too many models - theoretical and applied alike; let us cite de Palma et al. (2007), who measure local externalities and their effects on residential choices.

\subsection{Spatial competition - monopolistic and oligopolistic}

Urban economic models have long disregarded competition from differentiated products. And yet such competition was factored into the equation nearly a century ago by H. Hotelling (1929) ${ }^{6}$. His highly simplified model was exclusively spatial, although the beach on which his ice cream vendors moved about could be reread as a range of differentiation amongst products.

Product differentiation modelling has found an empirical counterpart in discrete choice models, the estimation of which is now operational. This approach achieved clear-cut success in residential location choice applications. Amongst the work in this field is that of Ben-Akiva and Lerman (1985), who popularised discrete choice models in the realm of transport. At the same time, differentiation concepts have come into their own in the field of urban economics thanks to the work of Alex Anas. This initial differentiation-based approach, which has become central to a majority of applied urban economic models, disregards competition, which nonetheless lies at the heart of the Hotelling model. 
Oligopolistic competition between firms that sell differentiated products and are spatially located was described for the first time by de Palma et al. (1985). To our knowledge, this approach has not yet been developed in connection with urban models. Nevertheless, these ideas have found a niche in one applied spatial context - that of international trade (Fajgelblum et al., 2011).

Not that competition is absent from urban economics: it came in massively in the form of monopolistic competition (intermediate between perfect competition and a monopoly situation), introduced by Chamberlin (1933) and analysed by Dixit and Stiglitz (1977). These ideas were taken up by the new geographical economics.

This description includes enterprises that have only slight market power, and it is well suited to a great number of small businesses, although less so to a number of large enterprises, each having monopoly power. Whether this approach can be used to describe competition between businesses within a major metropolitan area such as Paris, London or New York is still open to question. We feel that, in a sense, the choice of monopolistic competition is tantamount to overconfidence in the market. But this issue remains more empirical than theoretical.

Lastly, competition between large metropolitan areas, which is often forgotten by urban economics, is probably another instance of imperfect competition: it would in fact be gross oversimplification to assume that competing cities such as London and Paris constitute uniform options for multinationals wishing to establish their headquarters.

\section{THE NON-LINEAR MODELS APPROACH}

\subsection{Introduction}

The notion of developing operational models to describe the urban phenomenon, and later urban dynamics, came into its own with the advent of fairly powerful computers. Here we shall mention a number of the essential elements that we feel have been somewhat neglected in recent years.

An initial attempt to model urban forms was carried out by the (static) Metropolis model (Lowry, 1964). This simulation tool combines two types of space allocation: a residence location model and a location model for jobs and services. Here, a city's growth depends on the expansion of its basic, industrial sector, which determines the distribution of households and the resultant jobs. Basic sector jobs are constant, and in this sense the tool is a static one.

\subsection{Urban dynamics}

The history of large urban dynamics models begins officially with the work promoted by the Club of Rome, and thus the models of J.W. Forrester, whose celebrated Urban Dynamics was published in 1969. For the first time, it was thought possible to describe systems on a 1:1 scale (or almost) and to factor in a complexity inaccessible to analytical models. 
These approaches claimed inspiration from the work of Ludwig von Bertalanffy and Norbert Wiener. Very soon, use was made of systems theory which explored systems of interactions in terms of "boxes" and "arrows" to describe the processes of amplification and attenuation. The purpose of these studies was to regulate by introducing feedback loops: system inputs are a function of output values. To an economist, this conception of the propagation of effects evokes the dynamics of the Keynesian multiplier. From this perspective, a city is a large non-linear system modelled from the standpoint of regulation, so that in this case the work of urban designers, engineers and planners is to understand and make adjustments to regulation systems. The aim is to optimise management of the complex and highly non-linear system that is the city.

\subsection{Validation}

The data available for adjusting such a model were in many cases too few and insufficiently detailed to ensure the desired behaviour. This weakens the procedures for adjusting the model's parameters. Later, these procedures would be partially replaced by econometric estimation, which is more complex. But for the case at hand, the parameters were too numerous to adjust, making it impossible to devise satisfactory models.

\subsection{Interdisciplinarity}

Despite the pessimistic aspects, this first wave of modelling was useful because it liberated economics and urban planning from their rigid confines and exposed them to reality. It gave these disciplines applications with which to tackle the complexity of urban systems head-on. In this sense it played an ecumenical role.

\subsection{From modelling to reality}

Even so, all this expertise full of promise failed to satisfy the hopes that had initially been put in it: the city was still a vastly unpredictable system, and managing it was more often a matter of pragmatic policy and experience than the application of advice and recommendations stemming from any scientific expertise. But the wheel was turning.

We believe there were multiple reasons for the failure of this systemic modelling. Among the reasons explaining the relative failure of systems theory as a tool for regulating the city as a thermometer regulates temperature, we shall adopt the following:

Validation. Urban systems cannot be reduced to a series of non-linear equations reflecting the qualitative behaviours present as best they can. It is also necessary to look to a microscopic analysis of individual behaviours, which by nature are highly heterogeneous: the analysis of individual choices. This analysis came a bit too late in this first epic: its true development came only after the emblematic work linked to the Club of Rome.

Indeed, econometric decision models did not make their operational debut until the 1980s, and it was not until the 90s that they became commonplace (they can now be estimated very easily, with no need for user programming, through the use of commercial software such as SAS, GAUSS, ALOGIT or STATA, or shareware such as R or BIOGEME). 
As we shall see, this does not mean that discrete choice models can be used in conjunction with complex urban models. Much remains to be done before they are fully integrated.

Aggregation. The relationship between individual and aggregate behaviours is an issue that must lie at the core of our thinking. Yet this has to a large extent been disregarded by specialists in regional and urban economics (Schelling, 1971, being one notable exception), in contrast to the practice in other branches of economics, in which aggregation issues attract the attention of researchers, who probe relentlessly, for example, the relevance of the so-called "representative" individual.

Avoiding aggregation. The response of urban economics has increasingly been to shift from a somewhat ad hoc aggregated behaviour (using Cobb-Douglas aggregated functions) to an individual description of behaviours. In a sense, the viewpoint of urban economics is often that of "small is beautiful". What, in fact, could one think would be a more realistic world than one for which models have as many equations as agents: households (if not individuals) and businesses? Micro-simulation models, which nowadays are used more and more, illustrate this idea. For example, in the realm of transport, the aim is no longer to describe flows of identical vehicles, but of drivers, each of whom has objectives and individually distributed reaction speeds. In such models, each driver reacts according to the state of his or her immediate environment.

But when putting these models to the test, what is of concern to us is to ascertain whether they are capable of explaining macroscopic processes, such as a shock wave moving at low speed (depending on reaction time and a safe distance) in the opposite direction from traffic. If a driver arriving at $100 \mathrm{kph}$ off the motorway brakes suddenly (e.g. because a rabbit jumps out in front of the car), does the screen of the model show, as in reality, a braking front spreading backwards at roughly $20 \mathrm{kph}$, which corresponds to a macroscopic process? The answer to that question depends on the model, and it is affirmative for a number of microsimulation models of automobile traffic. In our view, alas, there is still no solution to this problem (which is still neglected by modellers of urban systems). Clearly defined strategies for testing and validating such models against shocks or drastic changes in policy must still be formulated. We shall come back to this issue later.

The systematic approach highlighted the importance of the non-linearities introduced by loops. Nevertheless, it is not enough to have succeeded in constructing a non-linear system; it is still necessary to know how to analyse its properties and ascertain the behaviours to be analysed. The matter of aggregating heterogeneous preferences in a highly non-linear system remains the core challenge of urban systems.

\subsection{Change of scale: the example of structuring}

To study the aggregation of behaviours is to describe the arrangements stemming from the aggregation. Are such arrangements bound to be disordered? No, because the thermodynamics of systems subject to non-equilibrium constraints have taught us that isolated systems alone are forced to see an increase in their entropy (we shall understand their degree of disorder). In contrast, non-isolated systems, which exchange energy or matter with the outside world, can see a decrease in their internal entropy production.

Physics and chemistry have given us outstanding examples of ordered structures emerging on the basis of local interactions. Everyone has heard about the Belousof-Zhabotinsky experiment (see YouTube), which features macroscopic spatio-temporal structures, unstable states undergoing complex transitions, sometimes linked by points of bifurcation, and between which there can arise 
periodic transitions, if not macroscopic chemical chaos (see de Palma and Lefèvre, 1983a and Prigogine, 1996).

The authors of these papers have also studied the behaviour of colonies of ants, which may participate, unbeknownst to them and in some cases by the millions, in gigantic edifices, the outfitting of which goes beyond - and way beyond - the cognitive and memorial capacities of an ant's brain. Are not such patterns mirrored by traffic jams, rhythmic applause in a concert hall or rumours or the spontaneous organisation of events by Facebook, for example? Clearly, such situations constitute extreme cases, archetypes that need to be tempered (here, see the approach of Mansour and de Palma, 1984).

\subsection{The case of cities}

In the case of cities, the rules of thermodynamics for isolated systems should not be applicable, and one does not in fact observe a shift towards disorder. It is therefore necessary to alter one of the premises of our problem. The second principle is compatible with the appearance of ordered structures under certain conditions: non-equilibrium constraints and the presence of interactions described by non-linearities ${ }^{7}$. Thus, just as an economic system that continuously gets richer even though no economic agent produces added value is suspect, so is any idea of a city that would structure itself with no description of its dealings with the outside world.

Models based on non-linearities and the system's interactions with the outside world emerged under the name of "dissipative structures" (i.e. structures that dissipate energy organising or structuring themselves, via interactions with the outside world). The concept of dissipative structure was introduced by Prigogine of the Brussels School (see Nicolis and Prigogine, 1977). It is close to the "synergy" concept introduced by Haken (see Haken, 1993 and Weidlich and Haag, 1987). In this new reference framework there arises the essential question of the stability of the states of such dynamic systems. In other words, to what extent can small causes trigger large effects in these macroscopic states? For example, is it possible that a reform of parking prices within Paris, or congestion charging in the very centre of Paris, could have effects throughout the Île-de-France?

Studies on Grand Paris have thus far disregarded traffic conditions and the companion measures to be instituted. Yet it could be contended, as we do, that the effects of the Grand Paris project will be felt not only in the areas adjacent to the new infrastructure, but throughout Île-de-France and beyond, in neighbouring regions. It is now possible to think system, to think local - but also non-local interactions in conjunction with analysis of non-linear and open systems, governed by a dynamic that is still fairly short-sighted but that goes well beyond the static and local visions of urban economists and their precursors, however systemic they may have claimed to be.

\subsection{Self-organisation}

Of course, residents are free to choose where they want to live, but apart from cases of anarchic urbanisation, such as, for example, the favelas of South America or the first gold rush to California, a series of engineering works, legislation and regulation governs such a dynamic. No one can say that Haussmann's work played no role in the urban development of Paris, let alone claim that if Haussmann had not existed, things would have followed the same course, the city being guided by forces of History beyond our capabilities for action. 
The most recent wave of models is grounded, far more seriously, in a dual approach based on individual behaviour and collective behaviour.

The balance between these two levels of interaction is tricky to achieve and to describe. We shall briefly describe two tools - RELU-TRAN and URBANSIM - which clash on many points while both being geared to the same objective: to describe, and if possible predict, the dynamics of large metropolitan areas.

\section{SETTING THE PARAMETERS OF GRAND PARIS STUDIES}

\subsection{Carving out Grand Paris}

One of the Grand Paris project's objectives is to reorient the region's economic development. A long tradition of centralisation has concentrated the bodies of power in Paris, thus polarising the city centre to the detriment of its peripheries, relegated to the role of residential suburbs.

For several decades, the tendency has been shifting towards decentralisation. But an addiction is not broken overnight. It will come as no surprise that the bold planning of the mid- $20^{\text {th }}$ century spoke of industrial decentralisation, and even of the industrialisation of country areas. It soon became understood that it was necessary not only to speak of under-industrialised regions, but that centres of gravity had to be assigned to the new maps that were to be drawn. Counterweight cities, as the large towns or metropolitan areas designed to serve as a balance to Paris were called, were obliged to interconnect their internal and regional spaces (Cohen, 2002).

The "new towns" experiments of the 1960s-1980s showed the limits of the policy of developing population centres. As a result, the government decided to develop centres of employment and research. This decision took shape with the establishment of competitiveness clusters, certain functions of which were subsequently taken over by territorial development contracts (CDTs). In June 2011 the Société du Grand Paris launched an initial call for tender for assessing the socio-economic consequences of the Grand Paris project. Team co-ordination entails harmonisation of working methods and consensus as to the carving out of the areas to be studied. Île-de-France comprises 1300 communes, and the 20 districts of Paris correspond to large communes in the broad sense.

UrbanSim can process a combination of 1300 areas (communes), whereas RELU-TRAN, which is more highly aggregated, can ideally model some fifty areas. A consolidation of communes into aggregated areas was proposed by the research team constituting one of the project's components. The starting point is the CDTs established in June 2011. After that, groups of communes are to be built around these CDTs, based roughly on the carving out of districts. Lastly, isolated/blocked-in communes are to be assigned to one of the already constructed areas - by default the neighbouring district to which it is most similar in terms of population density and located in the same département, or to a neighbouring CDT located in the same département if there is no choice. The perimeter of the CDTs has fluctuated considerably over time, with successive political and administrative decisions, and it has probably not stabilised. The proposed aggregated zoning thus differs at the margin from the official perimeters, in order to ensure coherence and socio-economic uniformity within each area, 
transcending political and economic divisions as well as stability in the definition of the areas' perimeter.

Figure 1: Potential CDT perimeters

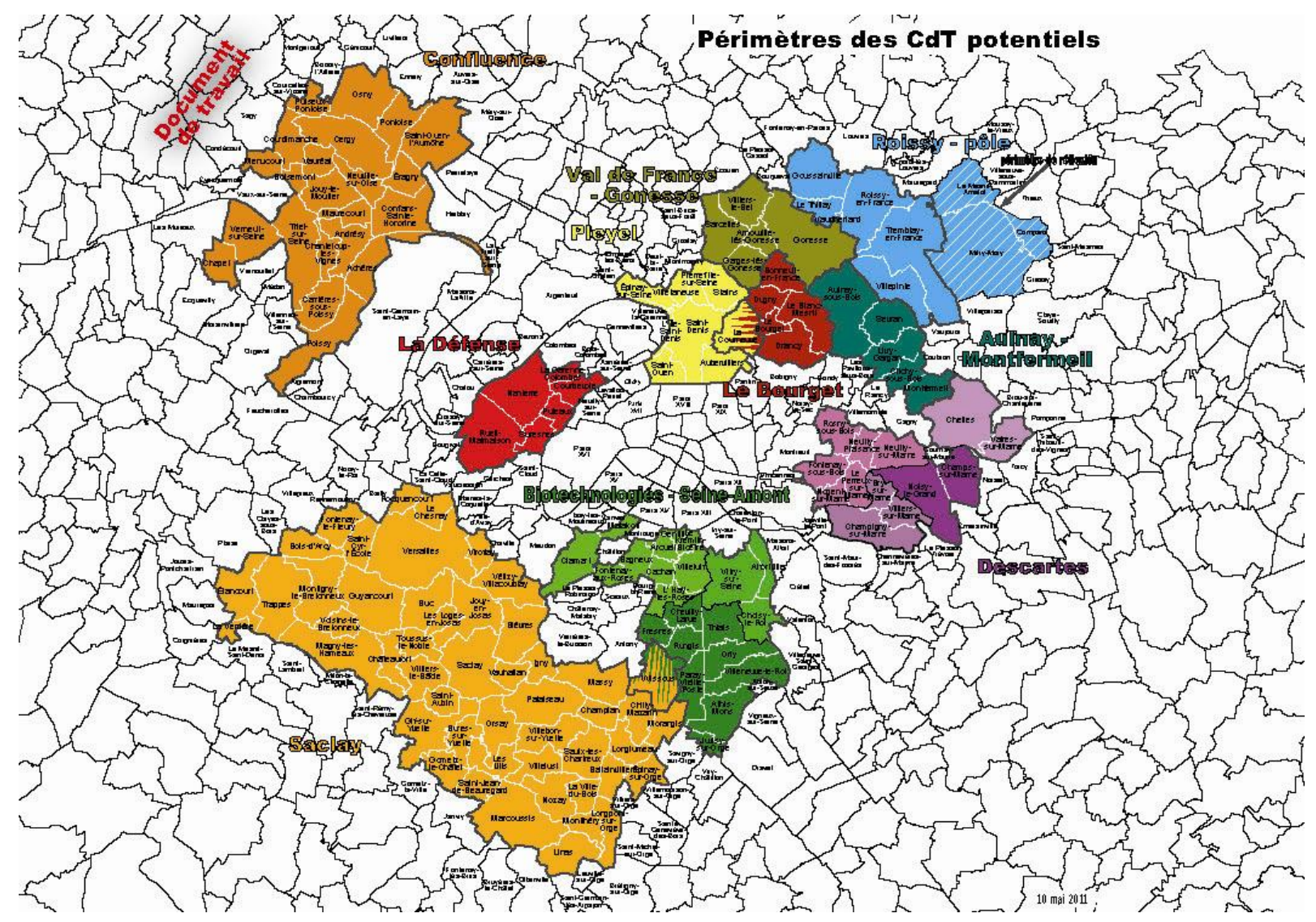

Source: DRIEA.

Initially (in 2009), there were seven development clusters ${ }^{8}$. Since 29 June 2011 there have been ten, namely: Confluence Seine-Oise, Est de la Seine-Saint-Denis, Est-parisien Cité Descartes, Gonesse Val de France, La Défense, Le Bourget, Plateau de Saclay, Roissy-Villepinte-Tremblay, Saint-Denis Pleyel and Biotechnologies Seine-Aval.

The perimeter of the ten Grand Paris competiveness clusters incorporates 150 communes of the Île-de-France region (170 including the 20 districts of Paris, the capital constituting an eleventh development cluster).

\subsection{Organisation of research}

It is difficult but necessary to impose a framework for the analysis of studies on Grand Paris. The major component elements of this are shown in Figure 2. This framework, while imperfect, can be used to map studies within a single diagram, which we hope will enhance thinking. 
Figure 2. Diagram of project analysis and evaluation tasks

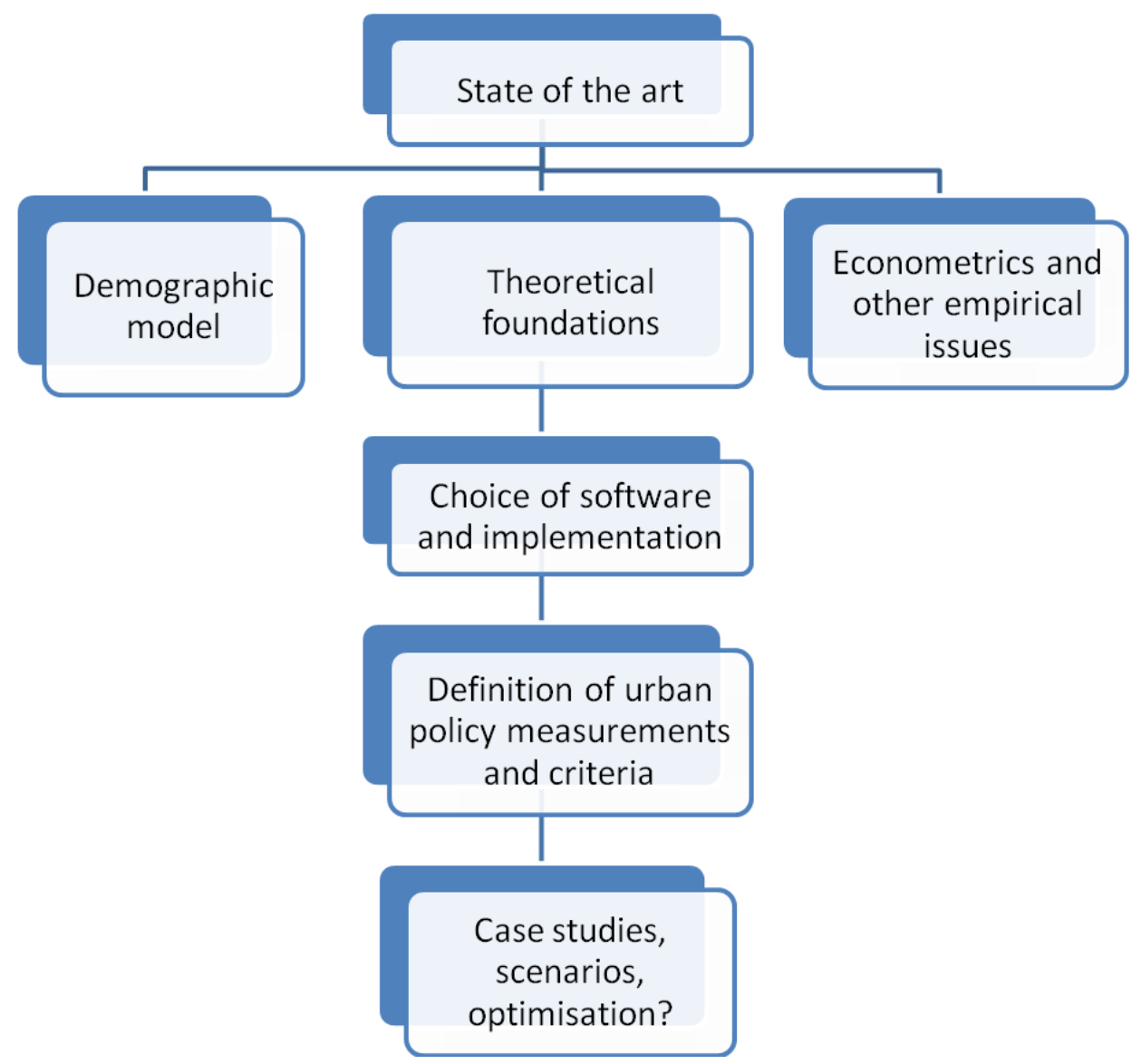

4.3. Angles of attack

State of the art. The premises of the operational models that have been developed have been drawn, more or less explicitly, from the broad theoretical corpus of urban, regional and spatial economics, and more recently from geographical economics (addressed succinctly in Section 3). Three disciplines should ideally be used in combination: (1) the economic/ geographical corpus of regional sciences; (2) econometrics; and (3) engineering and data processing as applied to the development of large models. Greater collaboration is needed between these disciplines so as to avoid a series of pitfalls, the most extreme of which are a theoretical model with no possibility of confrontation with data and an operational model based on $a d$ hoc - or even opaque - assumptions (which thus leave no room for discussion) and yielding no measures that overlap the concerns of theoreticians.

Data storehouses. Since the emphasis here is on a quantitative approach, analyses are dependent on data: transport, population and demographic trends, employment, land use and land prices. It is a known fact that data access and sharing are all too often an obstacle to modelling. 
Factoring in the long term. Studies to ascertain the impact of major infrastructure have a 10-, 30 - or even 50-year time frame. Long-term forecasting therefore plays an essential role here. The main considerations are:

$\rightarrow$ Economic trends in terms of growth (data extrapolated on the fly or not), but also shifting preferences: How could consumers' craving for utility vehicles have been foreseen?

$\rightarrow$ Changing technology. For example, what will the consequences of new information and communications technologies be on working conditions, mobility and agglomeration economies?

$\rightarrow$ Demographic changes, especially as shown by the long-term (from 30 to 50 years) models developed by the Institut National d'Études Démographiques, which has built up proven expertise in these fields. Factoring in the long term also entails the possession of projected rates of economic growth, employment, unemployment and so forth. In both cases, projections should ideally provide multiple scenarios providing inputs for the modeller. These inputs will be provided by the SGP once they have been compiled by the competent institutions.

Endogenous variables vs. exogenous variables. A crucial issue is whether variables are endogenous or exogenous. Studies on Grand Paris would adopt the idea that the demographic growth of Île-de-France is exogenous to economic development. Yet this is only partially the case, since a whole series of decisions that affect demographics are linked to the economy: marriages, divorces, births and women's participation in the labour market can hinge on housing conditions and mobility. Moreover, immigration into and emigration out of Île-de-France depend on the region's economic health. Such feedback loops are complex, and it is not certain that they can be incorporated into demographic models at a detailed spatial level anytime soon.

Choice of software. No software can do everything, but fortunately the tools are complementary. With respect to transport and land use models, two tools have been adopted to date for the Grand Paris project:

$\rightarrow$ RELU-TRAN, developed by Alex Anas (see Anas and Liu, 2007), is a general equilibrium model (for an introduction to general equilibrium models, we refer the reader to Brocker and Mercenier, 2011), which works in a semi-aggregated manner (50 areas and several hundred transport network nodes in the case of Île-de-France).

$\rightarrow$ URBANSIM(E), developed in connection with the European SustainCity project, constitutes the European version of URBANSIM (see Waddell, 2007 and Borning, Waddell and Forster, 2008). This is a microsimulation model that describes the behaviour of agents (households and businesses), land prices and modes of land use.

Both models adopt extreme positions with regard to dynamics: RELU-TRAN assumes that the system is in equilibrium, while URBANSIM(E) considers a process of adjustment from year to year which does not explicitly model the anticipation of agents.

\section{Formulating urban policy criteria}

Since these models give us no perception of the future per se, it remains to be ascertained how they can be used. Three types of uses can be distinguished (de Palma, 2009), each of which having its virtues. 
A first type of use is calculation, i.e. extrapolation. Its starting point is the principle that it is prudent to think that future states will prolong the trends which we detect with varying degrees of accuracy in the recent past. Infrastructure investments are thus frequently based on assessments made on the fly, on the basis of log-linear extrapolations of the growth rates of population and demand, for example. What actually happens? Such is its problem.

A second type of use consists of choosing objectives. This is clearly proactive and interventionist. Here, the starting point is the future: objectives have been assigned, and the task is to ascertain how to proceed, i.e. how to mobilise resources to achieve those objectives. For example, the choice of managing mobility based on a goal of cutting greenhouse gas emissions by $75 \%$ is an application of management by objectives. What must I do right? Such is its imperative.

A third type of use is to try to assess the local and overall sensitivity of the tools adopted. This will pay close attention to their elasticity with respect to changes in control parameters, but to changes in exogenous parameters as well. In its simplest version, it is a mere exercise in comparative statics. But if we assume that urban systems are truly non-linear, we therefore know, without being able to conclude anything from it, that small causes can produce large effects, and that changes in regime can occur. What can I feel from things? Such is its quest.

\section{Case study and scenarios}

All of these considerations are of interest to policymakers if they are presented properly. The assessment criteria are many. Too often they focus on physical measurements (such as levels of congestion and pollution and urban density).

$\rightarrow \quad$ These values can be enhanced by assigning them monetary values. Obviously, there arises the usual conflict between monetary values based on econometrics and those based on directives, which are less precise but also less subject to manipulation (for example, recommended discount rates or social values for time). Indices combining these values are more informative.

$\rightarrow$ These values are also enhanced by being combined in indices. Accessibility therefore plays an essential role in assessing infrastructure (see Poulit, 1974 and Weibull, 1980).

$\rightarrow$ Aggregated measurements are possible and desirable. They are not neutral. The social welfare function, which stipulates how the various values for variables can be added together, is in fact determined by the importance that the modeller wishes to assign to the city's various agents and players.

$\rightarrow$ Lastly, and although our discussion is not exhaustive, it is essential to analyse equity (vertical, but above all horizontal, i.e. spatial), which is often forgotten or ill-defined. This dimension is examined in Trannoy (2011) in connection with cost/benefit analysis. That discussion takes different orientations, depending on whether transfers between agents are possible or not. Trannoy considers measures that factor in equity issues according to the sharing of benefits and infrastructure costs.

A variety of evaluation criteria are conceivable, including rules based on the maximum minimum cost for access to services (the min-max criterion). As is often the case, it is not difficult to find examples for which the fair location of a public service is also totally ineffective: efficiency and equity do not go hand in hand. 


\subsection{The treatment of uncertainty}

The sources of uncertainty when modelling a project such as Grand Paris are legion, and this raises the following questions:

$\rightarrow \quad$ At what level should error terms be introduced, and how should these be specified to get the best fit between the structure of the models used and the reality being analysed?

$\rightarrow$ Are parameter values consistent across the various modules of an integrated model?

$\rightarrow$ Is knowledge of the present suitable?

$\rightarrow$ What are the errors in the projections of the states of reference?

The biases inherent in modelling can be tackled by performing a comparative study of the results of multiple models, comparing different scenarios, simulating qualitatively different events or explicitly acknowledging the existence of an uncertainty that will need to be factored into the analyses.

Lastly, there are a great many situations in respect of which the modeller cannot assign probabilities to events. In such cases one speaks of uncertainty. This does not mean that no modelling is possible, as we shall see later.

Let us elaborate on the meaning of these various ways of treating uncertainty. First we shall present what is derived from the scenarios. Each scenario characterises a situation that is deemed probable. Building consistent scenarios is always tricky, but a discussion with practitioners can lead to a better understanding of all the various configurations. A second way of factoring in the nondeterministic nature of the future is to simulate events. Here we use Monte Carlo simulation methods. It is therefore important to incorporate correlations between future events, such correlations being crucial to obtaining realistic scenarios. In this case, the future is seen as a set of possible trajectories (several hundred thousand simulations are needed to yield significant results from which relevant information must be derived on the basis of indicators).

In the presence of uncertainty, min-max or minimal regret criteria can be used as well.

Whatever its nature, the treatment of this uncertainty must be looked at critically. Presumably, it is necessary to be able to obtain the most probable modelling value for which these uncertainties can be translated into low and high ranges associated with the results obtained (see the example presented in Table 1).

Table 1: Simplified form of modelling results

\begin{tabular}{|l|l|l|l|}
\hline & Lower range & Most probable value & Upper range \\
\hline Accessibility & & & \\
\hline Agglomeration effects & & & \\
\hline Own dynamic & & & \\
\hline
\end{tabular}

Indices that are more elaborate can provide a better representation of the risk. These notions are the "value at risk" or the "conditional value at risk", which entail calculating the distribution of 
infrastructure rates of return. It should be noted that in the presence of risk or uncertainty, basic notions such as the internal rate of return are less able to remain operational in the presence of substantial fluctuations.

The presence of fluctuations raises questions about the bias that the "averaged" vision of the results may introduce. For example, let us take the case of a LogSum function, represented here as $\Omega(C)$, which hinges on the transport cost vector $C$. Numerous studies use the average cost, without reporting on the amplitude or value of the biases generated.

And yet it is easy to demonstrate that the use of LogSum in cases where costs are random will introduce a positive bias, i.e. that:

$$
E(\Omega(\mathrm{C}))>\Omega(\mathrm{E}(\mathrm{C}))
$$

This inequality results from Jensen's inequality and from the fact that LogSum is a convex cost function. In other words, accessibilities are underestimated when stochastic costs are replaced by average costs in accessibility formulas.

To summarise, if uncertainty is to be integrated consistently, the sources of uncertainty should be identified during the modelling process, and results should be presented with confidence intervals; indicators of results should be tailored to the degree of variability of measurements; and the direction and amplitude of bias should be controlled when deterministic variables are replaced by average values of random variables.

In conclusion, let it be noted that deterministic descriptions can under certain conditions be meaningless (see Mansour and de Palma, 1984). These authors show that by taking the stochastic version of a deterministic process, one can obtain a probability distribution, the least probable values of which correspond to the solution to the deterministic problem. The scope of interactions determines these conditions.

\subsection{Proximity effects}

Three types of proximity effects can be discerned:

(1) The profitability of business enterprises depends on the proximity of labour. Microeconomic theory suggests that salaries should in fact be adjusted to labour transport costs.

(2) Business productivity diminishes with the proximity of other businesses in the same category, given price competition.

(3) Businesses nonetheless tend frequently to select nearby locations. Technological spillovers depend on spatial proximity: exchange of information is in practice heavily affected by spatial proximity. Here, agglomeration forces are at work.

We shall see below how these ideas were factored into integrated land-use and transport interaction (LUTI) models. This list will remain incomplete as long as agglomeration effects are not factored in. 


\section{AGGLOMERATION EFFECTS}

\subsection{Introduction}

Cities are formed by combining two types of forces: agglomeration effects and "disagglomeration" effects. Disagglomeration effects are simple to describe and to quantify. They are responses to negative externalities generated by high levels of congestion associated with local pollution, noise and accidents. These effects are factored into existing transport models. Their incorporation into mobility and residence choices poses difficult but solvable econometric questions.

Remarkably, the situation is more complex when one speaks of agglomeration effects, which respond to positive externalities. Agglomeration effects correspond to an increase in business productivity (or a decrease in costs) as a function of the concentration of agents (see for example Anas, Arnott, and Small, 1998). These effects, while real, are ill-defined. They are often hidden behind the benefits of face-to-face contact (which will be difficult to explain to Internet or teleconferencing generations). One might ask why this Round Table that the OECD is hosting could not have been organised as an exchange of articles to be annotated. But watch out: this may be just what is done ten years down the road.

Moreover, the established fact of the existence of clusters of innovative businesses would suggest that it is in these firms' interest to locate in a common neighbourhood. This is true of the Research Triangle in North Carolina, which houses nanotechnology firms, of Massachusetts Route 128 near Boston, and of Silicon Valley in San Francisco Bay. The development of these three clusters and their induced regional effects were made possible by geographical proximity and local synergies: how, for example, could funds be raised and business angels found if young entrepreneurs have no opportunity to present their ideas in person? Employees have similar needs in terms of schedules, schools, and so forth, which induces agglomeration effects. Clearly, Internet makes it possible to send e-mails to all ends of the earth for the same price, and yet the fact remains that many e-mails are sent locally. Space induces the organisation of economic activities. And if local masses in turn modify spatial distances, this effect confirms, and does not contradict, the critical role of location.

These clusters, which are also to be found in Grand Paris, will be fully meaningful only if they trigger regional development; conversely, the neighbouring regional and urban densities encourage the development of clusters. Grand Paris deploys a complicated equation linking accessibility, urban development and technology clusters ${ }^{9}$.

\subsection{Empirical estimations}

If $P$ is productivity and $C$ is urban concentration (often associated with densities), then the elasticity of productivity with respect to urban concentration is:

$$
\epsilon=\frac{\frac{M P}{P}}{\frac{d C}{C}} .
$$


This elasticity is the ratio of the variation in productivity to the variation in urban concentration. If the elasticity is positive, it reflects agglomeration effects. Of course, this formula does not stipulate why these agglomeration effects are produced (via face-to-face, pooling of knowledge, espionage, technological spillovers, etc.).

Table 2 summarizes the results of literature on ranges of values for agglomeration effects.

Nevertheless, recent studies have shown that elasticities have often been overestimated: the gain in productivity that is observed in an urban environment, attributed to agglomeration effects, may stem from the fact that workers who are more highly skilled are attracted more by dense urban areas.

Table 2: Value of agglomeration effects: Summary of literature

\begin{tabular}{|l|l|l|l|l|}
\hline Author(s) & Country & Year & Sector & Elasticity \\
\hline Ciccone and Hall (1996) & USA & 1996 & Manufacturing & $6 \%$ \\
\hline Ciccone (2002) & $\begin{array}{l}\text { France, UK, } \\
\text { Germany, Italy }\end{array}$ & 2002 & Aggregated & $4.5 \%$ \\
\hline Rice et al. (2006) & UK & 2006 & Aggregated & $3.5 \%$ \\
\hline Henderson (2005) & USA & 2003 & Aggregated & {$[1.2 \% ; 13.5 \%]$} \\
\hline Combes et al. (2009) & France & 1860, & Agriculture & resp. 10\%, 10\% and -5\% \\
\cline { 4 - 5 } & & 1930 and & Industry & resp. 18\%, 11\% and 11\% \\
\cline { 4 - 5 } & & 2000 & Service & resp. 3\%, 11\% and 9\% \\
\hline
\end{tabular}

This hypothesis was tested by De La Roca and Puga (2010), who showed that if the worker effect is kept constant (by controlling the skills level of individuals), the elasticity of productivity with respect to density is lower, see Table 3 .

Table 3: Value of agglomeration effects with and without fixed effects

\begin{tabular}{|l|l|c|c|c|}
\hline Author(s) & Country & $\begin{array}{c}\text { Elasticity } \\
\text { without fixed } \\
\text { effect }\end{array}$ & $\begin{array}{c}\text { Elasticity with } \\
\text { fixed effect }\end{array}$ & $\begin{array}{c}\text { Reduction due } \\
\text { to introduction } \\
\text { of the fixed }\end{array}$ \\
\hline Combes et al. (2009) & France & $5 \%$ & $3.25 \%$ & $-35 \%$ \\
\hline Mion and Naticchioni (2009) & Italy & $2 \%$ & $0.66 \%$ & $-67 \%$ \\
\hline De La Roca and Puga (2010) & Spain & $5.1 \%$ & $2.5 \%$ & $-51 \%$ \\
\hline
\end{tabular}

These authors also discussed productivity gains as a function of time and location history. They concluded that some of the effects attributed to location result from a learning curve, as shown by the continuous growth in gains related to skill. They also show that these benefits are in part geographically mobile, as illustrated by the partial disconnect in salaries: e.g. decrease for a worker going from Madrid to Santiago, who will still be paid more than workers in Santiago. 


\subsection{Agglomeration effects in LUTI models}

$\rightarrow$ RELU-TRAN. According to Alex Anas ${ }^{10}$, there are three different kinds of agglomeration effects in RELU-TRANS. The concentration of the activities of agents (businesses or households) is determined by spatial heterogeneity (for example inhomogeneities inherent in transport networks); by interdependency between economic agents (who are dependent on transport costs, which increase with distance); and by positive synergies between agents (households and businesses that reap greater economies of scale, for example, if they serve larger markets).

$\rightarrow$ UrbanSim(E). Agglomeration effects can be incorporated into UrbanSim(E) in sub-models for the location of households and businesses.

For households, econometric analysis shows that residential location criteria depend on amenities, but also on population densities. Analysis of the data shows that households are sensitive to local densities, but also to the make-up of the population. This would imply that these models may potentially produce non-linear dynamics (see Section 3) and bifurcations. Basing their work on the interactive Markov chains approach, de Palma and Lefèvre (1983a and 1983b) studied the impact of positive and negative externalities in connection with a theoretical discrete choice model. Factoring agglomeration effects for businesses into UrbanSim(E) is possible but has not yet been done.

\section{ECONOMETRIC PRECAUTIONS ${ }^{11}$}

\subsection{The multinomial logit model and sampling of the alternatives}

To estimate agent location models (for households or businesses), a multinomial logit model is used frequently (see Ben-Akiva and Lerman, 1985 and Anderson, de Palma and Thisse, 1992). According to this model, the probability that agent $i$ locates in area $j$, offering local amenities $Z_{j}$, is given by the following formula:

$$
\mathbb{P}_{j}^{i}=\frac{e^{Z_{j} \beta_{i}}}{\sum_{j^{\prime} \in \mathcal{J}} Z_{j^{\prime}} \beta_{i}},
$$

where $\beta_{i}$ is a parameter vector corresponding to the marginal utilities of local amenities (preferences specific to household $i$ ). This vector can be dependent on the characteristics $X_{i}$ of the household to reflect the observable heterogeneity of preferences; it can include random terms corresponding to the non-observable heterogeneity of preferences. In this latter case, one speaks of mixtures of polytomic logit models, of which random coefficient models are among the most commonly used.

Ideally, local amenities are measured at a narrowly defined geographical level corresponding to a commune, an IRIS ${ }^{12}$ or a neighbourhood. In some cases, there are too many options $J$ to be able to estimate the model described by the multinomial logit model. This problem can be circumvented 
easily thanks to the option sampling technique: a small set of areas $\vartheta_{i}$ (typically about ten) are chosen at random, and for each household $i$ the probabilities for this option subset are estimated:

$$
\tilde{\mathbb{P}}_{j}^{i}\left(\mathcal{J}_{i}\right)=\frac{e^{Z_{j} \gamma_{i}}}{\sum_{j^{\prime} \in \mathcal{J}_{i}} Z_{j^{\prime}} \gamma_{i}}
$$

This procedure is both realistic from a behavioural standpoint and manageable econometrically. Assuming the independence of irrelevant alternatives (IIA), the parameters $\gamma_{i}$ estimated with option sampling constitute unbiased estimators of the parameters $\beta_{i}$ corresponding to the case in which each household's full range of choice is universal.

If the number of dwellings is unequal from one area to another, a correcting term corresponding to the size effect $\log \left(N_{j}\right)$, where $N_{j}$ represents the number of dwellings in area $j$, should be added to the list of local amenities. If one disregards the individual characteristics of dwellings, which are generally not observable, the dwellings of any one area may in fact be considered similar (hence the advantage of selecting sufficiently small areas). In this case, all of the dwellings in area $j$ have the same probability of being chosen by a given household $i$. Noted $\overline{\mathrm{P}}_{k}^{i}$, the probability that household $i$ would choose a dwelling $k$ located in area $j$ (local amenities therefore equal $Z_{k}=Z_{j}$ ) equals:

$$
\sum_{k \in j} \overline{\mathbb{P}}_{k}^{i}=\sum_{k \in j} \frac{e^{Z_{h^{\prime} \beta_{i}}}}{\sum_{j^{\prime} \in \mathcal{J}} \sum_{k^{\prime} \in j^{\prime}} e^{Z_{h^{\prime} \beta_{i}}}}=N_{j} \frac{e^{Z_{j^{\prime} \beta_{i}}}}{\sum_{j^{\prime} \in \mathcal{J}} N_{j^{\prime}} e^{Z_{j^{\prime}, \beta_{i}}}}=\frac{e^{Z_{j^{\prime} \beta_{i}+\log \left(N_{j}\right)}}}{\sum_{j^{\prime} \in \mathcal{J}} e^{Z_{j^{\prime \prime} \beta_{i}+\log \left(N_{j^{\prime}}\right)}}}
$$

In the above expression, the coefficient of $\log \left(N_{j}\right)$ is equal to unity, but that constraint disappears when the variance of the residuals is normalized to $\pi^{2} / 6$, as is customary in a multinomial logit model. Moreover, households may have preferences for the size of the area, measured by $\log \left(N_{j}\right)$, which constitutes an additional reason for not normalizing the coefficient of $\log \left(N_{j}\right)$ to one.

If dwellings are distributed unequally from one area to another and one wishes to draw options at random, the efficiency of estimations can be improved by the importance sampling technique, which consists of drawing options with a probability proportional to $N_{j}$.

\subsection{Embedded logit model}

Assumption IIA is generally subject to caution in a location model. It is tantamount to assuming that if an area that had a $10 \%$ probability of being chosen by household $i$ becomes inaccessible, then the probability of each of the other areas increases by an equal amount. But it is known that some areas are more substitutable between themselves than others, and that when one area becomes inaccessible to a given household, the probability that the household will locate in another area increases more than proportionally in respect of areas that are more substitutable and less than proportionally in respect of areas that are less substitutable. A simple solution is to construct an embedded logit model in which this household chooses a neighbourhood of a commune in an area: if this neighbourhood turns out to be inaccessible, the choice will shift to another neighbourhood of the 
same commune, etc. Observation shows that when households relocate they have a strong tendency to remain in the same département (see de Lapparent, de Palma and Picard, 2011).

\subsection{Endogeneity of prices in a location model}

An increase in local demand for housing triggers a rise in property prices. Conversely, all else being equal, an increase in local property prices causes the local demand for housing to decrease. When one wishes to estimate the price elasticity of demand for housing, one is therefore naturally confronted with the problem of the endogeneity of property prices.

In the presence of endogeneity, one simple solution is to make use of instruments - in this case the variables that influence property prices but have no direct effect on demand at fixed property prices. Yet all local amenities are necessarily going to influence property prices and demand for housing at constant property prices. It is therefore difficult to find an instrument in this context. In the event that housing and offices are in imperfect competition for land use, one might suppose that local taxation of businesses (but not of households) would be a potential source of such instruments. In the case of Île-de-France, the rate and bases of business tax have proved to be good instruments for correcting the endogeneity of prices in a residential location model.

\section{CONCLUSIONS}

The scope of research into the economic and social dimensions of Grand Paris is now open. The initial results of LUTI models are expected in the coming months. It will be interesting to compare these findings with those obtained in respect of other comparable large metropolitan areas, such as London, Moscow, New York, Tokyo or Beijing. The project's broad outlines having been finalised and approved, what remains is to be done, above all, is to find ways to turn this adventure into a series of surprises and favourable encounters.

The diversity of the players mobilised by this idea whose time has come inspires some optimistic - or at least mystical - ideas.

It is a known fact that one of the ideas pervading civic-minded discussions is yet another idea that seems like it could come straight out of thermodynamics: Density can be measured; intensity is felt. If social diversity, access to housing and work, and the visibility of urban landscapes are still attainable goals, it is because we are lucky enough to live in a part of the country that is blessed with a wealth of diverse and varied capabilities, where it will not be true that there is not enough for everyone.

If we are to be receptive to these visions of the future, let us conclude by reiterating our three rules for proper use. Attentive listeners will unfortunately have understood that they hardly give us any other choice except between the cane of the blind man's wanderings along the water's edge, the sumptuous prospects of the boundless sea of destiny beheld by the diver or the cautious - if not distrustful - toe of the traveller concerned about spying on other bathers. 
In a period of instability, subject as everyone is to strong non-equilibrium constraints, be they politicians, managers or entrepreneurs, the researcher, if unable to yield to the signs he thinks he can read in the stars or to heed the calls of his destiny, will endeavour to see which way the wind is blowing.

The psalmist, who knew a thing or two about lines in the sand and grandiose destinies, was wise enough to stay mum before undecipherable and deceptive futures:

Thy way is in the sea, and thy path in the great waters, and thy footsteps are not known.

With respect neither to the past, which we attempt to decipher, nor to the future, which we strive to construct, are we are assured of knowing where and how our efforts meet the reality of collective processes. This harsh conclusion is imperative each time we proffer the results of a calculation.

\section{NOTES}

1. I should like to thank the Société du Grand Paris and the International Transport Forum for giving me the privilege of sharing these thoughts with Round Table participants. I should also like to thank participants in the Grand Paris meetings held on the 15th and 25th of March 2011. In particular, my thanks go to C. Barbe (SGP), J.-J. Becker (CGDD), J.-V. Bonifas (SGP), G. Charasse (SGP), M. Gaudry, V. Gollain (ARD), P.-A. Jeanneney (SGP), C. Lecomte (CGEDD), S. Marchand (INSEE), F. Maurel (CGDD), A. Missoffe (SGP), J.-P. Ourliac (CGEDD), J. Poulit (DHUP), E. Quinet (ENPC), A. Sauvant (RFF), J. Senèze (SGP) and K. Van Dender (OECD). Lastly, I was also helped by comments from J.-C. Prager (SGP) and J.-F. Thisse (UCL), as well as by suggestions from N. Picard (UCP) and S. Pahaut (ULB). Some of the contents of this document are discussed in Beaude and de Palma (2011). Guillaume Monchambert contributed to the section on agglomeration economies. The researchers working on these projects and I had many fruitful discussions with Matthieu de Lapparent, who, in addition to this, found the time to reread and make comments on this manuscript. Stephen Perkins and Kurt Van Dender enabled us to improve the text.

2. These represent $70 \%$ of motorised trips in the Île-de-France. In addition, the modal share of public transport within the Paris city limits is $64 \%$, versus only $23 \%$ and $10 \%$ in the inner and outer peripheries, respectively.

3. According to INSEE, independently of this project one million additional people would be living in Île-de-France in 2030 if recent demographic and migratory trends continued (Leon, 2006).

4. For the Arc Express project (60 km long), the estimated cost is EUR 5 billion for the priority sections (north and south) and EUR 6 billion for the entire beltway.

5. It will be noted that this type of bidding mechanism is at the core of the urban general equilibrium model, MUSSA (this mechanism being explained by Martinez, 1996). 
6. However, see the historical note by Dos Santos and Thisse (1996) on W. Launhardt, Hotelling's predecessor back in 1885 .

7. Pierre Mongin, one of the Grand Paris stakeholders, recently stressed the fact that it was essential to model a city as an open system.

8. http://www.wmaker.net/grandparis/Les-7-poles-de-developpement-du-Grand-Paris_a277.html.

9. See also the articles from Round Table 140, The Wider Economic Benefits of Transport, and especially the articles by D. J. Graham and G. Weisbrod and B. Alstadt: http://www.internationaltransportforum.org/Pub/pdf/08rt140.pdf.

10. Source: slides prepared by Alex Anas for Grand Paris in 2011: A Regional Economy, Land Use and Transportation Model, RELU-TRAN.

11. Readers less familiar with technical issues may skip directly to the last section.

12. There are 1300 communes and 5200 IRIS in Île-de-France. 


\section{REFERENCES}

Anas, A., R.J. Arnott and K. Small, 1998, "Urban Spatial Structure”, Journal of Economic Literature, $36,1426-1464$.

Anas, A. and Y. Liu, 2007, "A regional economy, land use, and transportation model (RELU-TRAN): formulation, algorithm design and testing”, Journal of Regional Science, 47(3), 415-455.

Anderson, S., A. de Palma and J.-F. Thisse, 1992, A Discrete Choice Theory of Product Differentiation, The MIT Press: Cambridge.

Batty, M., 2008, "Fifty Years of Urban Modelling: Macro-Statics to Micro-Dynamics" in S. Albeverio, D. Andrey, P. Giordano and A. Vancheri, eds., The Dynamics of Complex Urban Systems: An Interdisciplinary Approach, Physica-Verlag, Heidelberg, 1-20.

Ben-Akiva, M. and S. Lerman, 1985, Discrete Choice Analysis: Theory and Application to Travel Demand, MIT Press: Cambridge.

Borning, A., P. Waddell and R. Forster, 2008, "Urbansim: Using simulation to inform public deliberation and decision-making", Digital Government: Advanced Research and Case Studies, 439-463.

Brocker J. and J. Mercenier, 2011, "General equilibrium models for transportation economics" in A. de Palma, R. Vickerman, R. Lindsey and E. Quinet, eds., Handbook of Transport Economics, Edward Elgar, Cheltenham, UK.

Chamberlin, E., 1933, The Theory of Monopolistic Competition, Cambridge, Mass., Harvard University Press.

Chiappori, P.-A., A. de Palma and Nathalie Picard, 2011, "Couple Residential Location and Spouses Workplaces" Columbia University, Department of Economics, mimeo.

Ciccone, A., and R.E. Hall, 1996, "Productivity and the density of economic activity", American Economic Review 86(1), 54-70.

Ciccone, A., 2002, “Agglomeration effects in Europe”, European Economic Review, 46(2), 213-227.

Combes, P-P., G. Duranton, L., Gobillon, D. Puga, D. and S. Roux, 2009, "The productivity advantages of large cities: Distinguishing agglomeration from firm selection" Discussion Paper 7191, Centre for Economic Policy Research.

de Lapparent, M., A. de Palma and N. Picard (2011), “A dynamic model of residential location and tenure choice" Centre d'économie de la Sorbonne, mimeo. 
De La Roca, J. and D. Puga, 2010, "Learning by working in dense cities" $36^{\text {th }}$ meeting of the Asociación Española de Ciencia Regional, Badajoz. Available at:

Princeton.edu/ erossi/CURE2010/esurban_seminar.pdf

de Palma, A., V. Ginsburgh, Y.Y. Papageorgiou and J.F. Thisse, 1985, "The Principle of Minimum Differentiation Holds under Sufficient Heterogeneity”, Econometrica, 53, 767-781.

de Palma, A., 2009, "Rational behaviour, Risk Aversion: High Stakes for Society", OECD Round Table 144, International Transport Forum, 23-49.

de Palma, A. and C. Lefèvre, 1983a, "Bifurcation and Behaviour of Complex Systems", Applied Mathematics and Computation, 14(18 B), 339-355.

de Palma, A. and C. Lefèvre, 1983b, "Individual Decision-Making in Dynamic Collective Systems", Journal of Mathematical Sociology, 9, 103-124.

de Palma, A., Kilani, M., De Lara, M. and S. Piperno, 2011, "Cordon Pricing in the monocentric city: theory and application to Paris Region" Louvain Economic Review, in Urban Studies and Economic Geography: A Special Issue in Honour of Masahia Fujita, F. Jouneau-Sion, and M. Kilani. eds., 77(2-3), 105-124.

de Palma A., K. Motamedi, N. Picard and P. Waddell, 2007, "Accessibility and environmental quality: inequality in the Paris housing market", European Transport, 36, 47-74.

de Palma, A., Picard, N. and Waddell, P. 2007, "Discrete choice models with capacity constraints: An empirical analysis of the housing market of the greater Paris region", Journal of Urban Economics, 62(2), 204-230.

de Palma, A. and O. Beaude, 2011, État de l'art des méthodes d'analyse socio-économiques dans le cadre d'un projet urbain, École Normale Supérieure de Cachan, Department of Economics and Business Administration.

Dixit, A. and J.E. Stiglitz, 1977, "Monopolistic Competition and Optimum Product Diversity", American Economic Review, 1977, 67 (3), 297-308.

Dos Santos Ferreira, R. and J.-F. Thisse, 1996, "Horizontal and Vertical Differentiation: The Launhardt model”, International Journal of Industrial Organization, 14, 485-506.

Fajgelbaum, P., G. Grossman and E. Helpman, 2011, Income Distribution, Product Quality and International Trade, Harvard University, Economics Department.

Forrester, J.W., 1969, Urban Dynamics, Productivity Press.

Fujita, M. and J.-F. Thisse, 2001, Economics of Agglomeration, Cambridge, University Press.

Haken, H. 1993, Advanced Synergetics: Instability Hierarchies of Self-Organizing Systems and Devices, New York, Springer-Verlag.

Henderson, J.V., 2005, "Urbanization and growth" in Aghion, P. and Durlauf, S., eds., Handbook of Economic Growth, Elsevier, 1543-1591. 
Hotelling, H. 1929, "Stability in Competition”, The Economic Journal, 39, 53, 41-57.

Krugman, P.R., 1995, Development, Geography, and Economic Theory, Cambridge, MA, The MIT Press.

Lafourcade, M. and J.-F. Thisse, 2011, "New economic geography: the role of transport costs" in A. de Palma, R. Vickerman, R. Lindsey and E. Quinet, eds., Handbook of Transport Economics, Edward Elgar, Cheltenham, UK.

Léon, O. and P. Godefroy, 2006, Projections régionales de population à l'horizon 2030, Technical report, INSEE Pôle emploi-population.

Lösch, A., 1940, Die räumliche Ordnung der Wirtschaft, Iéna, 1940.

Martínez, F.J., 1996, MUSSA: “A Land Use Model for Santiago City”, Transportation Research Record 1552: Transportation Planning and Land Use at State, Regional and Local Levels, 126134.

Mansour, M. and A. de Palma, 1984, "On the Stochastic Modelling of Systems with Non-Local Interactions", Physica, 128 a, 377-382.

Mion, G., and P. Naticchioni, 2009, "The spatial sorting and matching of skills and firms", Canadian Journal of Economics, Canadian Economics Association 42 (1), 2855.

Nicolis, G. and I. Prigogine, 1977, Self Organization in Non-Equilibrium Systems, J. Wiley and Sons: New York.

Overman, H. G., and Puga, D., 2010, "Labour pooling as a source of agglomeration: An empirical investigation" in E.L. Glaeser, ed., Agglomeration Economics, Chicago, Chicago University Press.

Poulit, J. (1974), Urbanisme et transport : les critères d'accessibilité et de développement urbain, SETRA, Division urbaine, Ministère de l'équipement, Paris.

Prigogine, Y., 1996, La fin des certitudes, Éditions Odile Jacob (with the collaboration of Isabelle Stengers).

Quigley, J.M. 2008, "Urban economics" in The New Palgrave Dictionary of Economics, S.N. Durlauf and L.E. Blume, eds., Palgrave Macmillan.

Rice, P., A. Venables and P. Patacchini, 2006, "Spatial Determinants of Productivity: Analysis of the regions of Great Britain”, Regional Science and Urban Economics, 36, 727-752.

Schelling, Thomas C., 1978, Micromotives and Macrobehaviour, Norton and Co., New York.

Strange, W C., 2008, "Urban Agglomeration" in The New Palgrave Dictionary of Economics, S. N. Durlauf and L. E. Blume, eds., Palgrave Macmillan.

Tabuchi, T., 2011, "City formation and transport costs" in A. de Palma, R. Vickerman, R. Lindsey and E. Quinet, eds., Handbook of Transport Economics, Edward Elgar, Cheltenham, UK, 
Thisse, J.F., 2011, "Geographical Economics: A Historical Perspective” Louvain Economic Review, in Urban Studies and Economic Geography: A Special Issue in Honour of Masahia Fujita, F. Jouneau-Sion and M. Kilani, eds., 77(2-3), 141-168.

Thünen, J. H. von, 1826, Der isoli[e]rte Staat in Beziehung auf Landwirtschaft und Nationalökonomie, Hamburg, Perthes, 1826.

Trannoy, A., 2011, "Equity dimensions of transport policies" in A. de Palma, R. Vickerman, R. Lindsey and E. Quinet, eds., Handbook of Transport Economics, Edward Elgar, Cheltenham, UK.

Waddell, P., G.F. Ulfarsson, J.P. Franklin and J. Lobb, 2007, "Incorporating land use in metropolitan transportation planning" Transportation Research Part A: Policy and Practice, 41(5), 382-410.

Weibull J.W., 1980, "On the numerical measurement of accessibility” Environment and Planning A, $12,53-67$.

Weidlich, W. and G. Haag, 1987, “A dynamic phase transition model for spatial agglomeration processes” Journal of Regional Science, 27, 529-569. 
E International

International Transport Forum

2 rue André Pascal

75775 Paris Cedex 16

itf.contact@oecd.org

www.internationaltransportforum.org 